\title{
Educação em ciências e cidadania: mudança discursiva e modos de regulação na política do Programa Nacional do Livro Didático
}

\author{
Science Education and citizenship: discursive change \\ and regulation practices in the Brazilian textbook policy \\ for public education
}

Rita Vilanova ${ }^{1}$

\begin{abstract}
Resumo: Este texto discute aspectos relativos à mudança discursiva que vem ocorrendo no campo da educação em ciências, na qual a educação para a cidadania assume uma posição de destaque. Com o objetivo de situar as tensões inerentes a essas mudanças e as perspectivas sobre cidadania que aí se inscrevem, nos debruçamos sobre relações que se estabelecem nas ações do Programa Nacional do Livro Didático. Para isso, nos apoiamos no arcabouço teórico-metodológico da análise crítica do discurso, e realizamos análises em trechos extraídos do Guia dos Livros Didáticos (Ciências). Nossas análises apontam para uma recontextualização dos discursos sobre ciência e cidadania que circulam em esferas do campo da educação em ciências no texto do PNLD. Nesse movimento, debates presentes na pesquisa em educação em ciências são recontextualizados adotando-se uma estratégia comunicativa típica das reformas, baseada em rupturas e substituições de um modelo por outro, que apagam as tensões inerentes às mudanças.
\end{abstract}

Palavras-chave: Educação em ciências. Cidadania. Discurso. Livro didático. Programa Nacional do Livro Didático.

\begin{abstract}
This paper discusses aspects related to the discursive change that is occurring in the field of science education, in which the purpose of citizenship assumes a central position. With the purpose of identifying and situating the tensions inherent to these changes and the different perspectives on citizenship, the relations established in the governmental regulation actions of school science textbooks production are discussed. Analyses were based on a Critical Discourse Analysis framework, and performed on excerpts obtained from the evaluation guidebook produced for public schools. Results point to a re-contextualization of the debates on science and citizenship performed in the field of science education research within the texts. The debates are re-contextualized, adopting a communicative strategy typical of the educational reforms, based on ruptures and replacements, which removes the tensions inherent to social change.
\end{abstract}

Keywords: Science education. Citizenship. Discourse. Science textbook. Programa Nacional do Livro Didático.

\footnotetext{
${ }^{1}$ Núcleo de Tecnologia Educacional para a Saúde (NUTES), Centro de Ciências da Saúde, Universidade Federal do Rio de Janeiro (UFRJ), Bloco A, Sala 33, Cidade Universitária, Ilha do Fundão, CEP 21941-902, Rio de Janeiro, RJ, Brasil. E-mail: <ritavilanova@ufrj.br>
} 


\section{Introdução}

A relação política é uma das muitas formas de relação de poder existentes entre os homens, e perpassa todas as dimensões da vida cotidiana. Seus fins, no entanto, não podem ser delimitados de forma definitiva, pois são tantos quantas são as metas que um grupo organizado se propõe, de acordo com os tempos e as circunstâncias (BOBBIO; MATTEUCCI; PASQUINO, 2007, p. 957). Hoje, os Estados democráticos são governados, embora em diferente medida, por meio de democracias representativas, nas quais as decisões da política são decididas por representantes eleitos pelo coletivo da população. De fato, atualmente, o modelo da representação pode ser considerado constitutivo das democracias, e quando nos referimos a Estados democráticos, subentende-se que estamos falando de democracias representativas.

No entanto, conforme avança a época contemporânea, muitos vêm defendendo que o Estado democrático não deve ser entendido como aquele no qual os cidadãos gozam somente das chamadas liberdades negativas, mas, também, das positivas, podendo participar, direta e indiretamente, dos assuntos públicos (BOBBIO, 2003).

Nas últimas décadas, estas noções vêm ganhando força em todo o mundo, e o debate sobre a construção de uma cidadania ativa e participativa inscreve-se nas mais diversas práticas sociais. A formação para a esta cidadania, por sua vez, passa a integrar a agenda de projetos educacionais, e, em muitos casos, aí incluído o brasileiro, a formação do cidadão assume a posição de finalidade última da educação. Por essa razão, a análise dos processos nos quais a formação para uma "nova” cidadania é destacada como finalidade da Educação Básica no Brasil torna-se relevante para a compreensão dos sentidos, limites e possibilidades dessas mudanças em nossa realidade educacional.

Neste contexto, a questão da educação para a cidadania destaca-se nas discussões sobre os objetivos da educação em ciências, estando presente nos mais diversos textos sobre o ensino desta disciplina. No entanto, ainda são incipientes as pesquisas e discussões mais fundamentadas sobre o tema na realidade educacional brasileira, e, embora pareça consensual a importância de se considerarem aspectos relativos à formação do cidadão na educação em ciências, existe pouco consenso sobre como operar com a inserção da temática nas esferas curriculares e pedagógicas.

Este trabalho tem como objetivo discutir os sentidos que a finalidade de educação para a cidadania adquire em documentos oficiais que atuam como um dos elementos reguladores da produção de livros didáticos para a educação pública no Brasil. Para isso, foi realizada uma análise discursiva do texto do Guia dos Livros Didáticos (BRASIL, 2007), documento que orienta a escolha dos livros didáticos utilizados na educação pública e faz parte do Programa Nacional do Livro Didático (PNLD), política do Ministério da Educação que avalia e compra as obras trabalhadas nas escolas. As análises que realizamos foram orientadas pelos pressupostos teóricos e metodológicos da análise crítica do discurso (ACD), uma abordagem que busca compreender como os discursos tomam parte nas mudanças sociais. O texto está organizado em três partes: na primeira, apresentamos brevemente uma análise da conjuntura política e econômica na qual mudanças nas finalidades da educação em ciências se inserem; em seguida, são apresentados os pressupostos teóricos e metodológicos que orientaram nossa pesquisa, e, na terceira parte, são apresentados alguns exemplos das nossas análises e algumas considerações sobre os resultados da investigação. 


\section{Análise de conjuntura: educação, cidadania e os projetos de reforma política}

A problemática da reforma e reestruturação do Estado constitui um tema central na política, em especial a partir da década de 1980, e está na origem de reorganizações de ordem política e jurídica que afetaram a gestão do público em todos os seus setores, em especial na educação, considerada área estratégica nas diferentes reformas de Estado (BARROSO, 2005).

Neste cenário de redefinição do papel do Estado, os objetivos de crescimento e promoção da competitividade econômica passam, em muitos países, a ser pensados em termos de uma nova forma de trabalho. Assim, as reformas educativas e a reestruturação dos sistemas educativos passam a ser pensadas à luz de mudanças mais globais no sistema capitalista, e, em muitos casos, incluindo-se, aí, o brasileiro, são idealizadas com base em uma forte conexão aos objetivos e às supostas necessidades do sistema produtivo e do sistema econômico, que transcendem, cada vez mais, o âmbito (e a capacidade de regulação) dos Estados nacionais.

Nesta conjuntura, a educação é importante para os países enquanto condição de competitividade, no sentido de permitir a entrada no novo modelo produtivo que necessita de uma mão de obra flexível, ou seja, capaz de se adaptar aos constantes avanços tecnológicos e reestruturações dos sistemas produtivos. Neste contexto, emergem os objetivos da "educação ao longo da vida", e do "aprender a aprender", termos que se tornaram habituais nos mais diferentes tipos de documentos sobre educação, em especial na década de 1990. A questão da cidadania também (re)emerge neste contexto, em geral, como resposta à fragilidade que os direitos sociais adquirem neste modelo produtivo, que se manifesta, sobretudo, no aumento dos índices de desigualdade e na constatação de formas precárias de inclusão social.

Neste sentido, a evocação simultânea da competitividade e da cidadania parece decorrer de um certo otimismo em relação ao que se supõe serem os efeitos positivos de uma generalização do sistema de produção pós-fordista. Um novo sistema de produção baseado na flexibilização da mão de obra demanda indivíduos com um novo perfil profissional. Neste modelo, o trabalhador com uma escolarização precária e desapropriado da sua subjetividade, criatividade e autonomia precisa ser substituído pelo trabalhador escolarizado, educado e qualificado, preparado para trabalhar em equipe, com capacidade de iniciativa e espírito crítico.

Numa análise mais específica do caso brasileiro, Burity (2006) destaca que, a partir de 1995, dois grandes processos relativamente independentes unem-se para produzir um novo discurso no campo das políticas sociais. O primeiro foi o processo de redemocratização ocorrido na década de 1980, que visava uma maior socialização da política, traduzida em uma participação mais ampla e independente da sociedade na esfera pública e nas políticas de governo, na descentralização do poder e na reestruturação do Estado que dá prioridade para a redistribuição e para o aumento do poder dos cidadãos. O segundo diz respeito à adoção de políticas de ajuste econômico e reforma do Estado inspirada por ideias neoliberais que buscavam uma hegemonia do capital e um estreitamento da esfera política.

No âmbito legal, este modelo de educação é regulamentado pela Lei de Diretrizes e Bases da Educação Nacional (Lei 9394/96), promulgada em 1996. A LDB é a lei maior da educação no país e define os parâmetros, os princípios e os caminhos a serem seguidos pela educação brasileira. Logo, as reformas estruturais do Estado, por meio de reformulações de suas competências, foram realizadas com maior intensidade e amparadas pelas mudanças legais. Ao mesmo tempo, foram implementadas as reformas no âmbito educacional que permitiriam 
tornar, segundo os órgãos governamentais, a educação formal brasileira compatível com a reforma geral do Estado (KRAWCZYK, 2005).

Um documento importante, que marca essa transição do ponto de vista curricular, são os parâmetros curriculares nacionais (PCN), propostos em 1998 (BRASIL, 1998). Os PCN podem ser considerados um documento-chave na reforma educacional brasileira, pois terminam por orientar políticas, como, por exemplo, as de avaliação e, também, a produção dos livros didáticos para todas as disciplinas².

O livro didático de ciências, por sua vez, vem sendo alvo, há muitos anos, de uma série de críticas. Tais críticas podem ser agrupadas em quatro eixos principais (VILANOVA, 2011): (1) do ponto de vista pedagógico, este instrumento didático é criticado por reforçar uma abordagem memorística dos temas científicos; (2) do ponto de vista curricular, por apresentar uma organização fragmentada do conhecimento científico; (3) do ponto de vista epistemológico, por apresentar uma concepção empirista e indutivista da ciência, e (4) do ponto de vista da política educacional, por não acompanhar as mudanças, sobretudo as curriculares e as demandas educacionais atuais.

Com base na noção de que o livro didático é um componente estruturante da educação escolar, autores como Amaral (2006), Höfling (2006), Megid-Neto e Fracalanza (2003), entre outros, destacam esse instrumento como um dos elementos que, juntamente com outros - vinculados à forma e à organização das instituições escolares -, reforçam e perpetuam os problemas que acabamos de mencionar.

Em resposta a esses problemas, os documentos produzidos para o ensino de ciências na esfera da política educacional (por exemplo, a Lei 9394/96, os Parâmetros Curriculares Nacionais, e as matrizes de avaliação de desempenho dos estudantes) vêm incorporando uma mudança discursiva, que, no interior da conjuntura que buscamos delinear aqui, inclui a educação para a cidadania como componente curricular desta disciplina. Em muitos casos, essas mudanças são realizadas a partir de interlocuções com a pesquisa na área de educação em ciências, com implicações para as bases curriculares, epistemológicas e pedagógicas desta disciplina escolar.

A partir deste problema, buscamos esclarecer o caráter heterogêneo dos textos que avaliam o livro didático, e como as mudanças mencionadas se inscrevem nos textos do PNLD. Buscamos, ainda, examinar como a questão da educação para a cidadania se relaciona com essas mudanças.

\section{Ensino de ciências e cidadania}

Ao buscarmos articular educação em ciências e cidadania, algumas especificidades precisam ser consideradas. Apresentamos, aqui, algumas ideias e propostas de articulação com

\footnotetext{
${ }^{2}$ Alguns exemplos podem ser encontrados nas avaliações do próprio Guia de Livros Didáticos de Ciências (BRASIL, 2007, p. 63; 92): (1): Na apresentação da proposta pedagógica, é mencionado, claramente, o construtivismo no ensino de ciências e os elementos teórico-metodológicos presentes no documento Parâmetros Curriculares Nacionais-PCN. Nesse sentido, as noções de procedimentos e habilidades, transversalidade e contextualização são centrais na proposta pedagógica oferecida; (2) Tendo como referência os PCN, a coleção coloca uma boa ênfase num currículo organizado por procedimentos e habilidades.
} 
modelos de cidadania liberal ${ }^{3}$, que constituem uma das ferramentas que utilizamos para explorar os dados da pesquisa relatada.

Uma iniciativa de elaboração de modelos que articulam ciência e cidadania pode ser encontrada em Barry (2000). O autor propõe três modelos, a saber: (1) Consumo da ciência; (2) Esfera pública, e (3) Pesquisa cooperativa.

1 Consumo da ciência: neste modelo, as finalidades da disseminação do conhecimento científico estão relacionadas com a escolha da ciência como algo válido para a vida das pessoas. Neste sentido, o objetivo vai além de ajudar as pessoas a compreenderem a ciência, reconhecendo que, na atual cultura do consumo, os indivíduos fazem escolhas mais de acordo com o que lhes é interessante e prazeroso do que de acordo com o que lhes é prescrito (BARRY, 2000). Do ponto de vista normativo, podemos considerar que o modelo de consumo da ciência está vinculado aos discursos liberais tradicionais de cidadania ${ }^{4}$, na qual a sociedade é regulada pelas leis de mercado e os cidadãos são concebidos de forma individualista e instrumental. Neste sentido, a prática da cidadania em situações que envolvam a ciência estaria vinculada às vantagens e benefícios individuais que a mesma possa oferecer.

2 Esfera pública: este modelo adota a perspectiva habermasiana ${ }^{5}$ de esfera pública e de cidadania. Assim, a ênfase deste modelo é no processo de formação de uma vontade política e de uma opinião pública. Nesta perspectiva, o reconhecimento da ciência como algo importante para a sociedade torna-se suficiente para que os indivíduos engajem-se no debate sobre as questões científicas. Isto significa que, neste modelo, é necessário reconhecer que os cientistas não detêm o monopólio sobre o conhecimento válido, no sentido de que não deveria haver um domínio do debate público por cientistas (BARRY, 2000). Estudos como os de Wynne (1996 apud BARRY, 2000, p. 2) defendem que os cientistas não possuem o monopólio sobre o conhecimento válido. Os cidadãos cientificamente ativos, neste sentido, são aqueles engajados criticamente no debate sobre as questões científicas. Com base neste argumento, Gil-Pérez e Vilches (2005) e DeBoer (2000) também defendem que os conhecimentos dos especialistas não garantem a adoção de decisões adequadas, e que perspectivas mais amplas e variadas são necessárias nas avaliações das repercussões das situações que envolvem ciência e público em médio e em longo prazo. Neste sentido, os cidadãos podem acrescentar contribuições significativas ao apresentarem perspectivas e interesses mais amplos.

Numa crítica a este modelo, Barry (2000) afirma que o problema aqui se relaciona com a dificuldade de se avaliar o conhecimento dos não-especialistas. Análises como a de Wynne são criticadas por romantizarem o conhecimento local, e por considerarem qualquer conhecimento válido. Por esta razão, nesta perspectiva, que tende ao relativismo, o envolvimento dos não-especialistas em questões que envolvem conhecimento especializado não teria como consequência o consenso racional, e sim levaria a mais antagonismos. Neste sentido, afasta-se da perspectiva habermasiana de esfera pública, onde o consenso é construído por um diálogo e uma negociação realizados em bases compartilhadas.

\footnotetext{
${ }^{3}$ Uma discussão mais aprofundada dos modelos de cidadania liberal e seus reflexos nos currículos de ciências pode ser vista em Vilanova e Bannell (2011).

${ }^{4}$ Ver Schumpeter (1970) e Habermas (2003) para uma discussão ampliada sobre o assunto.

${ }^{5}$ A teoria habermasiana de esfera pública pode ser consultada em Habermas (2003, 2004).
} 
3 Pesquisa cooperativa: proposto com base em um estudo desenvolvido por Callon e Rabeharisoa (1999 apud BARRY, 2000, p. 3), defende a possibilidade da contribuição de não-especialistas na produção do conhecimento científico. Neste modelo, o que emerge é uma divisão do trabalho complexa e negociada, composta por pesquisadores e não- especialistas ativos e interessados. Neste sentido, a conduta do cidadão científico ativo envolve um engajamento ativo no processo de pesquisa.

Este modelo também se aproxima da esfera pública, diferindo na forma de engajamento. De acordo com Barry (2000), o modelo anterior pressupõe um engajamento crítico, já no caso da pesquisa cooperativa, o conhecimento dos não-especialistas é considerado válido na própria construção do conhecimento científico.

A segunda proposta de modelos que articulam a ciência e a tecnologia é desenvolvida por Praia e Cachapuz (2005), com base no trabalho de Habermas (1987). De acordo com os autores, as relações entre a ciência e a técnica, como formas ideológicas de dominação na sociedade, foram desenvolvidas de maneira particularmente interessante por Habermas, que analisa as formas contemporâneas de relações entre tecnociência, as práticas políticas e a opinião pública. Habermas (1987) descreve três modelos de articulação: (1) tecnocrático; (2) decisionista, e (3) pragmático. Com base nos modelos apresentados na seção anterior, podemos inferir que os dois primeiros estão mais próximos do liberalismo clássico, e o último, do modelo habermasiano de esfera pública.

No modelo tecnocrático, os políticos dependem dos especialistas, os quais detêm o poder. A política é determinada, em grande parte, com base em conhecimentos científico-técnicos, com base na crença de que nos devemos deixar conduzir pela ciência e pela tecnologia, mesmo para resolver questões humanas.

O modelo decisionista é aquele em que a competência dos especialistas não substitui a ação política, e sim a coloca ao seu serviço. As escolhas éticas e os meios de concretização dos projetos científicos são separados artificialmente, e a escolha dos fins é guiada por valores vivenciados pelos não-técnicos. Os meios, no entanto, estão no âmbito de uma racionalidade técnica, ou seja, são guiados por conhecimentos técnico-científicos.

No modelo pragmático, a política é negociada entre técnicos e não-técnicos, entre políticos e cientistas, e entre ambos e a esfera pública. O modelo privilegia o aspecto comunicativo e persegue uma interação real entre os saberes técnicos e não-técnicos, e posiciona a esfera pública num lugar de obrigação em relação ao saber e à responsabilização. O modelo amplia as funções dos cientistas para além da produção de conhecimentos científicos e recomendações técnicas, obrigando-os a refletir sobre as consequências sociais que podem decorrer desses conhecimentos e dessas recomendações e, se necessário, a discutir estas com o público.

Nesta perspectiva, torna-se relevante problematizar os currículos que não situam a ciência nas suas relações com questões sociais, com a tecnologia e com o cotidiano das pessoas. Schibeci e Lee (2003) indicam que um dos caminhos para se atingir a educação em ciências para a cidadania é viabilizar meios para que a população possa questionar a Ciência ao levar em conta decisões pessoais e sociais, e veem, na imagem que a população constrói sobre a natureza da Ciência e do trabalho do cientista, um aspecto nodal para a construção de uma educação em ciências para a cidadania. 


\section{Análise Crítica do Discurso (ACD)}

Em maior ou menor grau, os textos fazem parte de, virtualmente, todos os eventos sociais. No caso de uma palestra, na redação de um jornal, ou na produção de um livro, a maioria das ações é de cunho linguístico. Numa partida de futebol, por exemplo, naturalmente, a maioria da ação é não linguística (FAIRCLOUGH, 2003, p. 48). De acordo com Fairclough, os textos são modelados, de uma maneira ampla, por dois poderes causais: por um lado, estruturas sociais e práticas sociais. Por outro, agentes sociais, as pessoas envolvidas nos eventos sociais.

Estruturas sociais são entidades bastante abstratas. Podemos pensar numa estrutura social como algo que define um potencial, um conjunto de possibilidades. Podemos citar, como exemplo: a estrutura econômica, a estrutura política, as classes sociais ou uma linguagem. Entretanto,

[...] a relação entre o que é estruturalmente possível e o que acontece de fato, entre estruturas e eventos é muito complexa. Eventos não são efeitos simples e diretos de estruturas sociais abstratas. Sua relação é mediada - existem entidades organizacionais intermediárias entre estruturas e eventos. Vamos chamá-las de 'práticas sociais'. (FAIRCLOUGH, 2003, p. 23)

Para a compreensão das relações linguísticas que se estabelecem na esfera das práticas sociais, Fairclough (2003) opera com o conceito foucaultiano de ordens do discurso. Uma ordem do discurso é uma rede de práticas sociais em seu aspecto linguístico, uma forma de organização e controle social da variação linguística (FAIRCLOUGH, 2001, 2003). Nessa perspectiva, é possível distinguir fronteiras e relações na totalidade de um conjunto estruturado de práticas sociais em domínios sociais específicos. No entanto, embora esses sistemas sofram uma série de regulações de acordo com o cenário histórico e social, os mesmos são abertos e passíveis de rearticulações e modificações por meio de elementos discursivos e, também, por outros aspectos sociais não discursivos.

A perspectiva teórica da ACD compreende a heterogeneidade dos textos como elemento essencial para o entendimento dos processos de produção textual. A interdiscursividade nos permite apreender como os discursos dialogam entre si, ou seja, como assimilam outros discursos no seu próprio discurso. O entendimento da interdiscursividade relaciona-se com a compreensão da heterogeneidade dos textos por meio dos elementos da ordem do discurso, operacionalizados na proposta teórica da ACD pela apreensão dos gêneros, estilos e discursos. Estas construções podem ocorrer de maneira normativa, tendendo a naturalização da ordem do discurso, ou de forma criativa, configurando novos elementos de ordem do discurso, uma vez que os limites entre estes elementos estão constantemente abertos para serem redesenhados à medida que estas são desarticuladas e rearticuladas no curso da luta hegemônica (FAIRCLOUGH, 2001).

Para a ACD, os gêneros são o aspecto especificamente discursivo das formas de agir e interagir no curso dos eventos sociais. Assim, quando analisamos um texto em termos de gênero, nós estamos perguntando como ele figura e contribui para a ação e interação em eventos sociais (FAIRCLOUGH, 2003).

Os gêneros discursivos, na metodologia de análise da ACD, podem ser agrupados em três categorias: (i) pré-gêneros: engloba categorias mais abstratas, podendo ser narrativos, 
argumentativos, descritivos, entre outros; (ii) gêneros desencaixados: associam-se a categorias menos abstratas, como entrevistas, artigos científicos, palestras. (iii) gêneros situados: gêneros que são específicos a redes particulares de práticas, como, por exemplo, uma entrevista etnográfica, ou um livro didático.

Os estilos, por sua vez, caracterizam em que medida pessoas se dirigem umas às outras, o que depende da natureza dos eventos, das relações entre as práticas sociais e as estruturas sociais e das capacidades dos agentes. Estes fatores possuem implicações nos diálogos estabelecidos e nas diferenças sociais. Assim, a questão aqui é em que medida existe simetria entre os agentes envolvidos nos eventos sociais, ou, ainda, em que extensão a estratégia comunicativa resulta na redução da diferença ou na falta de dialogicidade.

$\mathrm{Na}$ Análise Crítica do Discurso, os estilos podem ser analisados em termos de avaliações e modalidades. As avaliações são as formas mais ou menos explícitas ou implícitas nas quais os autores comprometem-se com valores. As avaliações são marcadas no texto, sobretudo, em termos do que é desejável ou indesejável.

As modalidades também se apoiam em níveis e tipos de compromisso do autor, em termos epistêmicos (compromisso com a verdade) e deônticos (compromisso com a obrigação/ necessidade).

Finalmente, os discursos, segundo Fairclough (2001), configuram formas particulares de construção dos textos, no sentido em que enfatizam determinados conteúdos e áreas do conhecimento de maneira bastante arbitrária, de acordo com os interesses institucionais. Neste sentido, os discursos podem ser entendidos como o conjunto de enunciados que, articulados por meio da linguagem, expressam os valores e os significados das diferentes instituições (MEURER, 2005). Para identificarmos diferentes discursos em um texto, podemos pensar no discurso como: (a) representando uma área particular do mundo (inclusive, áreas da vida social), ou seja, os 'temas principais', e (b) representando alguma perspectiva particular sobre os temas (FAIRCLOUGH, 2003).

De acordo com a perspectiva da ACD, podemos entender as representações discursivas como recontextualizações. Ao representarem um discurso em um texto, os autores o incorporam em um outro contexto, recontextualizando-o. Elementos dos discursos são seletivamente filtrados de acordo com as apropriações em cada contexto, sublinhando as diferenças entre as maneiras pelas quais um tipo particular de discurso é representado em diferentes campos, redes de práticas sociais, e gêneros.

A partir dessa perspectiva, essas práticas de seleção podem ser analisadas por meio das seguintes categorias: (i) presença: elementos dos discursos que estão envolvidos, presentes/ ausentes, proeminentes/com pouco destaque no texto; (ii) abstração: grau de abstração/generalização do evento concreto; (iii) organização: como os textos estão organizados; (iv) adições: o que é adicionado ao discurso representado, por exemplo, explicações/legitimações, avaliações.

No caso desta pesquisa, a análise das representações discursivas possibilita o delineamento dos diferentes sentidos da cidadania inscritos nos textos pesquisados, a que discursos estes respondem e, ainda, como são construídas interfaces entre a educação em ciências e a educação para a cidadania.

As pressuposições são representadas no texto por proposições que são consideradas por seus produtores como algo estabelecido, sendo, portanto, uma forma de incorporar outros textos, que podem ou não ter sido produzidos pelos sujeitos envolvidos na produção do texto analisado. Sistemas de valores associados a pressuposições podem ser encarados como perten- 
centes a discursos particulares. Por exemplo, em um discurso político e econômico neoliberal, temos a pressuposição de que tudo o que favoreça eficiência e adaptabilidade é desejável (FAIRCLOUGH, 2003). Em muitos casos, as pressuposições e os discursos aos quais se associam são considerados ideológicos. De acordo com o autor: "O trabalho ideológico dos textos está conectado com a hegemonia. Buscar por hegemonia é uma questão de buscar universalizar sentidos particulares com o objetivo de adquirir e manter a dominação, e seu trabalho é ideológico" (FAIRCLOUGH, 2003, p. 58).

As ressuposições podem ser sinceras ou manipulativas, ou seja, podem apresentar uma proposição como estabelecida com objetivo de manipulação do leitor, uma vez que tais proposições são frequentemente difíceis de desafiar. $\mathrm{Na}$ abordagem da ACD, as pressuposições podem ser proposicionais (pressuposições sobre o que algo é, pode ou poderá ser); existenciais (pressuposições sobre o que existe) ou valorativas (pressuposições sobre o que é bom ou desejável).

É importante ressaltar que não podemos assumir que um texto possa tornar-se transparente por meio da aplicação de categorias contidas numa estrutura analítica preexistente. Ou seja, o que nós somos capazes de ver está relacionado e depende da perspectiva na qual abordamos o problema, incluindo as questões em foco, a teoria social e a teoria do discurso na qual nos baseamos.

\section{Metodologia}

O Guia de Livros Didáticos do ano de 2008 (BRASIL, 2007) é organizado em um volume de apresentação e mais um para cada disciplina dos anos finais do Ensino Fundamental (história, geografia, ciências, português e matemática). O volume de apresentação traz uma série de recomendações e esclarecimentos sobre o programa, e, ainda, o formulário de escolha das duas opções de livros para todas as disciplinas.

O volume referente à disciplina Ciências é organizado numa seção de apresentação, na qual são expostos os pressupostos epistemológicos, curriculares e pedagógicos que nortearam a elaboração dos critérios de avaliação. Em seguida, esses critérios são apresentados ${ }^{6}$, seguidos por um quadro comparativo das categorias avaliadas em cada coleção, e da avaliação propriamente dita.

De acordo com o referencial teórico apresentado nesta seção, as análises realizadas nesta pesquisa foram desenvolvidas com base nos gêneros, estilos e discursos, por meio dos quais buscamos discutir os sentidos que a cidadania vem adquirindo nas recomendações para a educação em ciências. No caso dos discursos, foram analisados, na pesquisa, vinte e três segmentos extraídos da seção de apresentação do Guia, dos quais sete são apresentados neste artigo, em decorrência das limitações de espaço desta comunicação. Para a análise do gênero, trabalhamos com as categorias propostas pela ACD, em diálogo com as análises desenvolvidas nos segmentos. Além destes segmentos, foram extraídos cinco exemplos da comunicação entre o texto e o leitor, para a análise dos estilos. Estes segmentos e exemplos representam todos os trechos em que se perceberam sugestões manifestas de mudança e, também, o desenvolvimento de articulações entre educação em ciências e cidadania.

${ }^{6}$ Os critérios de avaliação nesta edição do Programa foram: proposta pedagógica, conhecimentos e conceitos, pesquisa, experimentação e prática, cidadania e ética, ilustrações, diagramas e figuras, e manual do professor. 


\section{Resultados: educação em ciências e cidadania no Guia dos Livros Didáticos (PNLD 2008)}

Passamos às análises do texto do PNLD 2008. É pertinente relembrar, nesse momento, que os trechos analisados são transcrições do texto de apresentação do Guia dos Livros Didáticos 2008 (Ciências), onde o sentido de mudança é manifesto e nos quais realizamos a análise discursiva.

\section{Discursos}

\section{Segmento 1}

1 A análise centrou-se em aspectos científicos, metodológicos pedagógicos, éticos e estéticos definidos de acordo com os novos pressupostos para o ensino de Ciências, configurados pela pesquisa na área e pelas diretrizes curriculares atuais [...]

5 Este Guia foi organizado utilizando-se outros conceitos igualmente importantes: o respeito e a liberdade para escolher e tomar decisões partindo dos princípios de exercício da cidadania. Dessa forma, a estrutura deste Guia pretende criar oportunidades para que vocês, em conjunto com os demais professores de Ciências de sua escola, possam definir a melhor forma de estudo de seus conteúdos com vistas à tomada de decisão quanto à escolha da coleção. (BRASIL, 2007, p. 11-12)

Neste segmento, destaca-se o posicionamento adotado pelos produtores do texto no que se refere aos pressupostos definidos para a análise dos livros didáticos em seus aspectos científicos, metodológicos éticos e estéticos. Note que o uso do termo definidos (linha 2), representa uma escolha e um posicionamento que se alinha com o que os autores classificam como novos pressupostos para o ensino de Ciências (linha 3). Podemos destacar aqui uma pressuposição existencial, vinculada à relação entre as pesquisas na área da educação em ciências e as diretrizes curriculares atuais. Da maneira em que se apresenta no texto (linhas 3 e 4), os autores definem uma interlocução entre as diretrizes curriculares atuais e a pesquisa na área da educação em ciências naturais, que resultam em novos pressupostos para o ensino desta disciplina, os quais o Programa adota na avaliação das coleções didáticas.

\section{Segmento 2}

1 Fazer perguntas e produzir respostas, comunicando-as a outros, é a essência da construção de um processo de argumentação e comunicação que auxilia na aprendizagem de conhecimentos e procedimentos de ciência e sobre a ciência. Esses processos

5 ajudam o cidadão a entender como a ciência funciona e como utilizá-la na solução dos problemas do seu cotidiano, bem como 
a opinar sobre as questões que envolvem conhecimento científico e tecnológico. (BRASIL, 2007, p. 14)

Neste segmento, identificamos a presença de discursos humanistas sobre educação em ciências - alinhados aos modelos da esfera pública (BARRY, 2000) e pragmático (HABERMAS, 1987), com destaque para a ênfase nos processos de argumentação e comunicação. Nas linhas 3 e 4 , temos a pressuposição proposicional de que esses processos auxiliam a aprendizagem de conhecimentos e procedimentos de ciência e sobre a ciência. Nessa formulação, o discurso representado inscreve-se por meio da utilização do vocábulo sobre, ou seja, ao aprender sobre os conhecimentos e procedimentos de ciência, soma-se, às finalidades do ensino desta disciplina, a compreensão da ciência e dos seus processos. Formulações desse tipo são frequentes na literatura da educação em ciências de ênfase humanista, assim como a afirmação das competências de argumentação e comunicação na educação científica.

Representando esse mesmo discurso, nas linhas 5 a 8, temos a afirmação de que essa abordagem das ciências podem auxiliar o cidadão em dois níveis: no enfrentamento dos problemas do seu cotidiano e na formação de opiniões sobre questões sociocientíficas.

\section{Segmento 3}

1 O aprender reconstrutivo tem seus fundamentos na linguagem. Aprende-se ciências falando, lendo, escrevendo, desenhando, ou envolvendo-se em outras formas de linguagem. São diferentes formas de produzir novos significados, especialmente quando na

5 interação com outros. Aprender ciências pela linguagem é mais do que adquirir novos conhecimentos: é tornar-se parte da cultura científica, sabendo tomar parte ativa no discurso e no poder da ciência. (BRASIL, 2007, p. 15)

Neste segmento também está representado o discurso humanista sobre educação em ciências. Note que a ênfase aqui está nas questões de linguagem e do papel nos processos de participação na cultura científica. Neste sentido, aqui os autores assumem uma posição epistemológica que reconhece a ciência como parte integrante da cultura, em consonância com a "nova filosofia da ciência" (CLEMINSON, 1990 apud CACHAPUZ et al., 2005, p. 129).

Por meio de uma pressuposição proposicional, infere-se que aprender ciências pela linguagem permite a inserção na cultura científica, e que esta prática instrumentaliza os estudantes para a participação no discurso e no poder da ciência. O discurso sobre cidadania marcado aqui está próximo daqueles que se inscrevem no modelo pragmático e de esfera pública de cidadania, no qual a apreensão da linguagem da ciência possibilita: argumentar racionalmente sobre questões sociocientíficas, criticar a ciência, negociar com especialistas, e identificar as maneiras com que a ciência e a tecnologia causam impactos futuros. 


\section{Segmento 4}

1 Assumir a aprendizagem como processo de saber operar com o conhecimento científico implica em valorizar na educação em ciências a prática da cidadania, visando à formação de sujeitos socialmente participativos. (BRASIL, 2007, p. 18)

\section{Segmento 5}

1 Para isso, é fundamental a substituição do currículo convencional de ciência, centrado na transmissão dos conhecimentos científicos clássicos, pouco relevantes para a vida dos alunos, por um currículo centrado no desenvolvimento

5 de conhecimentos, competências, valores e atitudes, visando à formação da cidadania. (BRASIL, 2007, p. 18)

\section{Segmento 6}

1 Isto significa adotar no ensino de ciências a perspectiva Ciência, Tecnologia e Sociedade (CTS) de currículo de modo a preparar alunos participativos para atuar de forma coresponsável em processos coletivos de tomada de decisão

5 sobre assuntos relacionados com a Ciência, a Tecnologia e a Sociedade, inclusive com o meio ambiente. (BRASIL, 2007, p. 18)

\section{Segmento 7}

1 Ao aprender ciências dessa perspectiva, os alunos se assumem parte do esforço dos seres humanos de ampliar cada vez mais a compreensão do meio em que vivem e de poder intervir nele. Não basta adquirir conhecimentos, mas é preciso saber

5 manejá-los no sentido de resolver problemas novos que constantemente emergem em seu meio. Isso constitui uma verdadeira prática de cidadania. (BRASIL, 2007, p. 18)

Os segmentos de número 4 a 7 versam, especificamente, sobre as relações entre educação em ciências e cidadania. No Segmento 4, temos a pressuposição proposicional de que assumir a aprendizagem como processo de saber operar com o conbecimento científico (linhas 1 e 2), tem como decorrência a valorização da prática da cidadania. Esta concepção de educação em ciências, conforme apontado na discussão anterior, inscreve-se no discurso das perspectivas humanistas sobre o ensino desta disciplina, e valoriza o desenvolvimento de competências de argumentação e de participação no discurso e no poder da ciência. Destacamos, nas linhas 3 e 4, a articulação da prática da cidadania com a formação de sujeitos socialmente participativos, que, de acordo com a concepção de ensino discutida nos segmentos acima, inscreve-se nos discursos sobre educação em ciências fundamentados nos modelos pragmático e da esfera pública. 
O Segmento 5, por sua vez, toca a questão do currículo e defende a sua substituição. Isso é feito por meio de uma pressuposição valorativa em termos do que é fundamental para a educação em ciências - a substituição dos currículos convencionais. Isso também é feito por meio de uma pressuposição proposicional que, neste caso, afirma a existência de um currículo pouco relevante para a vida dos alunos, e propõe a organização de currículos de acordo com as finalidades propostas nos Parâmetros Curriculares Nacionais - o desenvolvimento de conhecimentos, competências, valores e atitudes visando à formação da cidadania (linhas 5 e 6).

Como decorrência dessas pressuposições, no texto do Segmento 6, temos a afirmação da perspectiva Ciência-Tecnologia-Sociedade (CTS) como alternativa aos currículos convencionais. Neste segmento, as finalidades de formação para a cidadania do currículo também apontam para os modelos pragmático e da esfera pública, por meio da finalidade de instrumentalização dos alunos para atuar de modo participativo e corresponsável em processos coletivos de tomada de decisão (linhas 3 e 4). No Segmento 7, por meio de uma pressuposição valorativa, temos a apresentação de mais uma finalidade do currículo nessa perspectiva. Aqui, temos um exemplo da convergência entre os discursos de formação para o trabalho flexível e a formação para a cidadania (AFONSO; ANTUNES, 2001; LOPES, 2002; TEDESCO, 1999).

Com base nas análises realizadas até aqui, podemos afirmar uma ampla predominância dos discursos de cunho humanista da educação em ciências no texto de apresentação do Guia dos Livros Didáticos, e nos critérios de avaliação da categoria Cidadania e ética. Isto é feito por meio de uma série de pressuposições proposicionais e valorativas, que criticam as práticas convencionais de educação em ciências e defendem a inclusão das orientações curriculares, pedagógicas e epistemológicas desenvolvidas a partir das discussões e relatos de alguns setores de pesquisas atuais sobre a educação em ciências.

Os sentidos da cidadania, por sua vez, podem ser discutidos em três níveis distintos. O primeiro, com base no ponto de vista normativo, aponta para a predominância dos modelos de esfera pública, com a ênfase em um ensino de ciências que instrumentalize os estudantes para a argumentação, a compreensão da natureza da ciência e da sua linguagem, como base para uma participação ativa e informada nos debates sobre questões que envolvem a ciência e a sociedade. Neste sentido, com base nos discursos da cidadania científica, destacamos a apropriação dos enunciados presentes nos modelos Pragmático (HABERMAS, 1987) e da Esfera Pública (BARRY, 2000).

O segundo sentido que identificamos está relacionado à posição ímpar que o conceito de cidadania assume no cenário político e social atual, sendo adotado nas mais diferentes esferas da vida social, em especial nos textos políticos. Note que já na primeira frase do texto da seção O ensino de ciências e o livro didático (Segmento 5 - linha 1), o termo cidadão é evocado, num sentido bem próximo do pontuado por Carvalho (2009, p. 7): "ela [a cidadania] substituiu o próprio povo na retórica política. Não se diz mais ‘o povo quer isto ou aquilo', diz-se a cidadania quer. Cidadania virou gente."

Finalmente, com base nas nossas análises podemos definir a formação para a cidadania como elemento legitimador da mudança discursiva que vem ocorrendo nas esferas acadêmica e da política educacional, inscrita no texto que analisamos. Inicialmente, o exercício da cidadania é empregado no sentido da legitimação da própria metodologia do PNLD (ver a análise do Segmento 2), por meio da apresentação dos conceitos e valores nos quais esta política pública afirma se basear. 
No caso mais específico da educação em ciências, as finalidades de formação para a cidadania emergem como justificativa para: a introdução da finalidade de compreensão da natureza da ciência (Segmento 2), a substituição dos currículos de ciências (Segmentos 5 e 6) e o desenvolvimento de aptidões para a resolução de problemas que envolvam a ciência (Segmento 6). Do ponto de vista epistemológico, as mudanças sugeridas apontam para a substituição de uma percepção de natureza empirista/indutivista por uma baseada na perspectiva desenvolvida pela literatura contemporânea sobre filosofia da ciência ${ }^{7}$.

\section{Gêneros}

De acordo com as conceituações apresentadas anteriormente, podemos situar o Guia dos Livros Didáticos na categoria dos gêneros desencaixados, ou seja, como um gênero pouco abstrato, que circula em diferentes ordens do discurso e eventos sociais. Como outros exemplos deste gênero, podemos citar guias de viagens e guias médicos. Os guias, de uma forma geral, fornecem orientações, sugestões e descrições, de acordo com as finalidades das atividades em que se inserem.

De acordo com o que discutimos na seção anterior, o Guia dos Livros Didáticos, considerando suas especificidades, apresenta uma série de orientações e sugestões que incorporam uma série de mudanças, que, de acordo com os autores, podem contribuir para a substituição de práticas consideradas inadequadas para a formação dos estudantes do Ensino Fundamental. Assim, o que é desejável aqui é que os leitores sigam as orientações do guia, e a expectativa é de que as interações entre as equipes pedagógicas e o texto possam melhorar as práticas de educação em ciências nas escolas.

Nas análises da seção anterior, podemos destacar, no Segmento 1, as relações manifestas do que é esperado na interação entre o texto e o leitor. A evocação de valores como liberdade e respeito são enfatizadas como as bases dessa relação, nos marcos do exercício da cidadania. Da mesma forma, na produção do Guia, são ressaltadas as noções de representatividade, diversidade e cooperação.

Assim, nos casos das relações esperadas entre o texto e o leitor, no contexto mais amplo das regulações do processo de avaliação, escolha e compra de livros didáticos, cabe problematizar algumas questões. De acordo com Barroso (2005), a diversidade de fontes e modos de regulação faz com que as relações políticas que se estabelecem em um sistema educativo resultem mais da interação dos vários dispositivos reguladores do que da aplicação linear de normas, regras e orientações oriundas do poder político.

Assim, no que tange aos aspectos discursivos das interações e ações que ocorrem no Programa, podemos discutir os dois eventos que ocorrem separadamente na sua execução: o da elaboração do guia, realizada por uma equipe de consultores contratada pelo MEC e coordenada por uma Universidade, e o evento de escolha do livro pelas equipes de ciências que atuam nas escolas. Vale destacar que a primeira parte do processo é feita de forma centralizada, marcando uma relação bastante vertical entre a seleção das opções de livros didáticos e a escolha das coleções. De acordo com o texto do Guia, esta etapa foi feita considerando-se os princípios de

\footnotetext{
${ }^{7}$ Algumas discussões sobre o tema podem ser consultadas em Aguiar (2001) e Cachapuz, Praia e Jorge (2004).
} 
representatividade, diversidade e cooperação. Nos marcos da cidadania liberal, esta separação aponta para o discurso do liberalismo político tradicional, no qual a política tem por função reunir os interesses sociais e mediá-los por meio do aparato estatal (HABERMAS, 2003). Nessa etapa centralizada, conforme buscamos demonstrar, temos um discurso que se materializa a partir da interação entre os discursos oficiais sobre educação em ciências e os discursos produzidos na pesquisa da área da educação em ciências. A etapa seguinte, por sua vez, ocorre na interação deste texto com as equipes de ciências nas escolas, que é atravessada por uma série de negociações e ajustamentos regulados por questões mercadológicas - por exemplo, as estratégias de marketing das editoras - e, também, pelas concepções de educação em ciências e ações presentes nas escolas e seus atores, que discutiremos quando abordarmos os estilos.

Esse evento - no qual as escolhas das coleções didáticas são feitas pelas equipes de ciências - ocorre a partir de uma interação entre a esfera organizacional do PNLD e as escolas públicas. Esta interação é feita por meio do preenchimento de uma ficha ${ }^{8}$, na qual os professores e coordenadores optam por dois títulos presentes no Guia. Não podemos deixar de mencionar que, em muitos casos, os títulos escolhidos não são os títulos que chegam, de fato, às escolas. Embora de forma ligeira, o próprio Guia admite essa falha ${ }^{9}$ faz um mea culpa:

Os professores entrevistados analisam como muito importante este processo de avaliação do livro didático, pois se sentem apoiados uma vez que a tomada de decisão pode ser partilhada. Entretanto, gostariam de ver "contemplada a escolha do livro indicado pela escola". (BRASIL, 2007, p. 10, grifo dos autores)

Neste sentido, a liberdade e o respeito, ou seja, as bases nas quais o Programa afirma partilhar as decisões sobre a escolha dos livros, parecem ser prejudicadas por aspectos organizacionais e mercadológicos. Embora esse não tenha sido o foco da pesquisa, vale mencionar que uma série de autores vêm apontando para questões problemáticas no que tange aos modos de regulação das relações políticas que se estabelecem nas relações entre o mercado editorial, o PNLD e a escolha do livro didático pelas escolas ${ }^{10}$.

\section{Estilos}

A análise dos estilos, de acordo com nosso referencial metodológico, tem como objetivo principal o delineamento das estratégias comunicativas que se configuram em um texto. Alguns exemplos são apresentados a seguir, retirados dos segmentos que extraímos da seção de apresentação do Guia analisados nas seções anteriores.

\footnotetext{
${ }^{8}$ Disponível em: <http://portal.mec.gov.br/seb/arquivos/pdf/2008/pnld08_ciencias.pdf>. Acesso em: 30 set. 2014.

9 O Guia dos Livros Didáticos 2008 abre a seção "A escolha dos livros didáticos nas escolas" com a menção de uma pequena pesquisa realizada junto a professores de diversas regiões do país. Segundo o Guia, o objetivo da pesquisa foi conhecer um pouco melhor o processo de escolha dos livros didáticos nas escolas (BRASIL, 2007). ${ }^{10}$ Para análises mais aprofundadas dessas questões, ver, por exemplo, Höfling (2006) e Amaral (2006).
} 
- Exemplo 1: "Isso implica romper com uma cultura rotinizada por algumas teorias e práticas [...]” (BRASIL, 2007, p. 14) - linhas 3 e 4.

- Exemplo 2: "Um ensino de ciências baseado em tais pressupostos, juntamente com uma reconstrução do conhecimento do aluno, visa também ao entendimento da natureza da ciência, dos seus modos de funcionamento. Aprender ciências é também conhecer os métodos da ciência, suas dificuldades e como se produzem as teorias científicas ao longo do tempo. É aprender a manipular suas ferramentas e saber utilizá-las na reconstrução social. É reconhecer que toda descoberta tem um autor e um contexto social e histórico. [...]” (BRASIL, 2007, p. 16) - linhas 1 a 11.

- Exemplo 3: "Superar o entendimento de aprender como armazenamento de conhecimento e compreender que é importante envolver-se nos processos das ciências implica em ampliar o conceito do que são conteúdos a serem aprendidos em ciências" (BRASIL, 2007, p. 16) - linhas 1 a 3 .

- Exemplo 4: "Assumir a aprendizagem como processo de saber operar com o conhecimento científico implica em valorizar na educação em ciências a prática da cidadania..." (BRASIL, 2007, p. 18) - linhas 1 a 3.

- Exemplo 5: "Para isso é fundamental a substituição do currículo convencional centrado na transmissão dos conhecimentos científicos clássicos, pouco relevantes para a vida dos alunos, por um currículo centrado no desenvolvimento de conhecimentos, competências, valores e atitudes, visando à formação da cidadania" (BRASIL, 2007 p. 18).

Nestes exemplos, podemos identificar a função prescritiva dos enunciados nos exemplos 1, 3 e 4, que abordam a necessidade de mudanças no ensino de ciências e o que é indispensável para que essas sejam atingidas. No caso das necessidades de mudanças, os autores empregam os verbos romper, superar e assumir, no que tange às atividades necessárias às mudanças, temos o uso recorrente do verbo implicar (em negrito nos trechos). Essas modalidades (deônticas) apontam para o compromisso dos autores com o que eles consideram imprescindível para uma boa educação em ciências.

O Exemplo 2, por sua vez, emprega uma série de asserções sobre o que é ensinar ciências (destaque em negrito no texto). As asserções, conforme já comentado, indicam o compromisso do autor com a verdade. De acordo com os graus de compromisso nas modalidades epistêmicas propostas por Halliday (1994 apud FAIRCLOUGH, 2003, p. 82), neste exemplo, podemos considerar um grau alto de compromisso com a inserção dessa perspectiva de educação em ciências no livro didático. De forma semelhante, o exemplo 3 apresenta o mesmo grau de compromisso, só que, neste caso, por meio da afirmação do que é fundamental para que a mudança ocorra, a saber, a substituição de um currículo por outro.

Se entendermos a "regulação do sistema educativo" como um "sistema de regulações", precisamos considerar o papel fundamental das instâncias (indivíduos, estruturas formais ou informais) de mediação, tradução, passagem dos vários fluxos reguladores (BARROSO, 2005). Para Barroso (2005, p. 735), nestes locais, são feitas as sínteses e se superam os conflitos entre as várias regulações existentes: "Estas instâncias funcionam como uma espécie de "nós da rede" de diferentes reguladores e a sua intervenção é decisiva para a configuração da estrutura e dinâmica do sistema de regulação e seus resultados".

Neste sentido, e de acordo com as acepções da ACD, as formas de comunicação que se estabelecem entre essas esferas - no caso que nos interessa, as interlocuções entre a política de livros didáticos e as equipes que realizam a escolha dos livros - são importantes para a 
implementação de mudanças. Por esta razão, alguns aspectos que destacamos nas análises do estilo merecem ser problematizados.

Nas análises do estilo, destacamos uma série de prescrições e asserções sobre a educação em ciências. Conforme apresentado na seção anterior, os estilos caracterizam em que medida pessoas se dirigem umas às outras, o que depende da natureza dos eventos e das capacidades dos agentes. Estes fatores possuem implicações nos diálogos estabelecidos, que resultam na redução das diferenças ou na falta de dialogicidade. Nas análises do estilo, destacamos um alto grau de comprometimento com as mudanças de cunho epistemológico que vêm sendo defendidas por muitos como possibilidade de aprimoramento das práticas educativas e, num sentido mais amplo, de democratização da cultura cientifica, em contraposição a uma visão autoritária da ciência. Ou conforme apontam Praia, Cachapuz e Gil-Pérez (2002, p. 134),

O que está em causa é evitar que a atividade científica seja apenas apresentada como informação final ou mesmo um mero conhecimento adquirido, sem a necessária compreensão de como se lá chegou, dos processos e dos contextos. Importa passar-se a atribuir significado central ao conhecimento científico e assim poderemos falar de verdadeira compreensão científica, cumprindo uma das expectativas de hoje da sociedade em geral e da comunidade educativa em particular - o sucesso educativo de todos, enquanto utopia, mas também como meta final a perseguir e a construir, a abraçar pela Escola em conjugação de esforços com todas as forças e movimentos sociais.

No entanto, da maneira como se apresentam no texto, esses debates são recontextualizados na forma de uma retórica de conclusões, por meio de uma série de prescrições e asserções, que terminam por criar posições bastante assimétricas entre o texto e o seu leitor. Conforme buscamos apontar no decorrer deste trabalho, as perspectivas atuais sobre a educação em ciências não são consensuais, e são atravessadas por tensões que, em última análise, precisam ser negociadas nas atividades que ocorrem no interior das escolas e das salas de aula de ciências. Essas tensões, no entanto, são ausentes no texto, que adota, em termos de estilo, uma estratégia comunicativa típica das reformas, baseada na asserção de rupturas e substituições.

Um outro aspecto, complementar ao que acabamos de discutir, relaciona-se às bases necessárias para o diálogo com as propostas atuais para o ensino de ciências que acabamos de mencionar. De acordo com essas perspectivas, no que se refere à educação em ciências, a excessiva simplificação da estrutura e do papel desempenhado pelas teorias tem, como consequência, uma ideia de ciência finalizada, que apaga a característica de questionamento contínuo e de dúvida em face da forma final do produto apresentado. Estudos empíricos de investigação em educação em ciência vêm demonstrando que as concepções de ciência que os professores possuem têm implicações no modo como a ensinam (PRAIA; CACHAPUZ; GIL-PÉREZ, 2002). A partir dessa premissa, muitos vêm defendendo a criação de espaços e tempos em que o professor: tenha acesso às principais concepções de ciência, possa refletir sobre elas, confrontá-las, aprofundando as suas próprias concepções e, a partir daí, formular indicações, orientações e princípios quanto às estratégias e procedimentos a adotar no seu trabalho docente (PRAIA; CACHAPUZ; GIL-PÉREZ, 2002). No entanto, esse percurso de pesquisa/teoria/ prática exige reflexão, tempo, maturação de ideias, cumplicidade com a inovação e empenho 
na ação (CACHAPUZ; PRAIA; JORGE, 2004). Desta forma, cabe problematizar, aqui, as possibilidades de diálogo com as bases epistemológicas que fundamentam o PNLD - Ciências, considerando-se o arcabouço da formação da maioria dos professores de ciências brasileiros. De acordo com Praia, Cachapuz e Gil-Pérez (2002, p. 129),

Muitos investigadores educacionais referem mesmo que os avanços no ensino das ciências serão limitados enquanto a educação em ciência for deixada a professores ou a formadores de professores sem bases teóricas e desvalorizando a reflexão epistemológica. Dito de outra maneira, o tempo de serviço não é qualificação para uma análise crítica em nível epistemológico.

Retomando nossas discussões sobre os discursos representados no Guia dos livros didáticos, cabe pontuar, aqui, que, de acordo com nossas análises, as mudanças de cunho epistemológico afirmadas no texto em geral são legitimadas pelos objetivos de formação para a cidadania. Os livros didáticos que se inscrevem no edital do PNLD para avaliação precisam responder a essas demandas, ao mesmo tempo em que precisam passar pelo crivo dos professores, cuja maioria não compartilha do repertório de conhecimentos sobre epistemologia necessários ao diálogo com as recomendações do Programa.

\section{Conclusões}

As mudanças sugeridas nos textos da política dos livros didáticos, conforme buscamos discutir nas seções anteriores, recontextualizam as recomendações para a educação em ciências presentes nos textos das pesquisas atuais na área da educação em ciências. No entanto, pudemos destacar que os debates e tensões inerentes às mudanças discursivas acabam por sofrer um certo apagamento. Esta forma de comunicação, típica das reformas, em face da complexidade dos processos de regulação das políticas públicas de educação, vem sendo problematizada por autores como Barroso (2005) e Ball e Bowe (1992), pois os processos de ajustamentos e reajustamentos que operam nas diversas instâncias do sistema escolar tornam improvável o sucesso de estratégias de mudança desta natureza.

Um outro problema que procuramos ressaltar nas análises do texto do PNLD, e complementar ao que acabamos de mencionar, refere-se às relações entre o texto e o leitor, no que tange as capacidades dos agentes, ou seja, as aptidões e conhecimentos necessários para o diálogo com o texto do PNLD no processo de escolha do livro didático. Buscamos problematizar a questão das bases necessárias para o diálogo com as perspectivas mais atuais da educação em ciências, em geral contidas nas propostas e discussões sobre o letramento científico e sobre as relações ciência-tecnologia-sociedade.

Esta discussão aponta, necessariamente, para o entendimento de como as mudanças que destacamos se inscrevem nos currículos dos cursos de formação inicial e continuada de professores de ciências, pois, conforme já citado, somente a experiência não fornece as bases para o diálogo com os fundamentos epistemológicos que orientam as propostas e iniciativas de mudança na educação em ciências. De acordo com Praia, Cachapuz e Gil-Pérez (2002, p. 131), 
[...] desejável mesmo é que, de algum modo, o professor não assente o seu saber sobretudo na informação, mas que possa também desenvolver conhecimentos e saberes no modo como se investiga, como se faz ciência. O ter conhecido e, se possível, experimentado os lados privados da ciência ajudam a reflexão epistemológica e permitem uma agilidade e capacidade para transferir para a ação o que se pensa muitas vezes (incorretamente), que pode ser feito de forma direta - do saber teórico-informativo para o saber prático e refletido.

Assim, o que está em jogo aqui são as possibilidades de se atingir uma maior simetria entre os agentes envolvidos nas relações entre a esfera de produção das políticas para a educação em ciências e a esfera da prática pedagógica. Conforme já discutido, a extensão na qual existe uma maior ou menor simetria entre os agentes nos eventos sociais pode refletir em uma redução das diferenças, ou na falta de dialogicidade. Neste sentido, consideramos que mais pesquisas sobre as bases epistemológicas inscritas nos processos de formação docente são relevantes para uma apreensão mais abrangente deste problema, partindo-se do pressuposto de que as visões que os professores possuem da ciência possuem implicações nas formas como eles a ensinam.

Buscamos mapear as possibilidades e limitações do processo interdiscursivo, que entendemos como um trabalho ideológico, que busca universalizar os novos sentidos que vêm sendo construídos sobre a educação em ciências, e que, por sua vez, são atravessados pelos discursos de formação para a cidadania. Estes sentidos se contrapõem àqueles já estabelecidos nesta área da educação, o que tem como consequência novas hibridizações e algumas contradições, que se manifestam, sobretudo, no nível epistemológico, conforme buscamos apontar em nossas análises.

\section{Referências}

AFONSO, A. J.; ANTUNES, F. Educação, cidadania e competitividade: algumas questões em torno de uma nova agenda. Cadernos de Pesquisa, São Paulo, n. 113, p. 83-112, 2001.

AGUIAR JR., O. Mudanças conceituais (ou cognitivas) na educação em ciências: revisão crítica e novas direções para a pesquisa. Ensaio: pesquisa em educação em ciências, Belo Horizonte, v. 3 n. 1, p. 1-25, 2001.

AMARAL, I. A. Os fundamentos do ensino de ciências e o livro didático. In:

FRACALANZA, H.; MEGID-NETO, J. (Org.). O livro didático de ciências no Brasil. São Paulo: Komedi, 2006. p. 83-123.

BALL, S. J.; BOWE, R. Subject departments and the "implementation" of national curriculum policy: an overview of the issues. Journal of Curriculum Studies, London, v. 24, n. 2, p. 97-115, 1992. 
BARROSO, J. O Estado, a educação e a regulação das políticas públicas. Educação e Sociedade, Campinas, v. 26, n. 92, p. 725-751, 2005. (Número especial).

BARRY, A. Making the active science citizenship. In: 4S/EASST CONFERENCE, 2000, Vienna. Worlds in transition: technoscience, citizenship and culture in the 21 st century. Vienna: University of Vienna, 2000.

BOBBIO, N. O filósofo e a política: antologia. Rio de Janeiro: Contraponto, 2003.

BOBBIO, N.; MATTEUCCI, N.; PASQUINO, G. Dicionário de política. Brasília: Editora UnB, 2007.

BRASIL. Ministério da Educação. Guia de livros didáticos: PNLD 2008 - ciências. Brasília, 2007. Disponível em: <http://www.dominiopublico.gov.br/download/texto/me004857. pdf>. Acesso em: 08 jul. 2008.

BRASIL. Ministério da Educação. Parâmetros curriculares nacionais: ciências naturais. Brasília, 1998.

BURITY, J. A. Reform of the State and the new discourse on social policy in Brazil. Latin American Perspectives, n. 33, p. 67-90, 2006.

CACHAPUZ, A.; PRAIA, J.; JORGE, M. Da educação em ciência às orientações para o ensino das ciências: um repensar epistemológico. Ciência \& Educação, Bauru, v. 10, n. 3, p. 363-381, 2004.

CACHAPUZ, A. et al. A necessária renovação no ensino das ciências. São Paulo: Cortez, 2005.

CARVALHO, J. M. Cidadania no Brasil: o longo caminho. Rio de Janeiro: Civilização Brasileira, 2009.

DeBOER, G. E. Scientific literacy: another look at its historical and contemporary meanings and its relationship to science education reform. Journal of Research in Science Teaching, Hoboken, v. 37, n. 6, p. 582-601, 2000.

FAIRCLOUGH, N. Analysing discourse: textual analysis for social research. London: Routledge, 2003.

FAIRCLOUGH, N. Discurso e mudança social. Brasília: UnB, 2001.

GIL-PEREZ, D.; VILCHES, A. The contribution of science and technological education to citizens' culture. Canadian Journal of Science, Mathematics \& Technology Education, Philadelphia, v. 5, n. 2, p. 85-95, 2005.

HABERMAS, J. Direito e democracia: entre facticidade e validade. Rio de Janeiro: Tempo Brasileiro, 2003. v. 2.

. A inclusão do outro: estudos de teoria política. São Paulo: Loyola, 2004.

Técnica e ciência como "ideologia". Lisboa: Edições 70, 1987. 
HÖFLING, E. M. A trajetória do Programa Nacional do Livro Didático do Ministério da Educação no Brasil. In: FRACALANZA, H.; MEGID NETO, J. (Org.). O livro didático de ciências no Brasil. São Paulo: Komedi, 2006. p. 20-31.

KRAWCZYK, N. R. Políticas de regulação e mercantilização da educação: socialização para uma nova cidadania? Educação e Sociedade, Campinas, v. 26, n. 92, p. 799-819, 2005. (Número especial).

LOPES, A. C. Os parâmetros curriculares nacionais para o ensino médio e a submissão ao mundo produtivo: o caso do conceito de contextualização. Educação e Sociedade, Campinas, v. 23, n. 80, p. 386-400, 2002.

MEGID-NETO, J.; FRACALANZA, H. O livro didático de ciências: problemas e soluções. Ciência \& Educação, Bauru, v. 9, n. 2, p. 147-157, 2003.

MEURER, J. L. Gêneros textuais na análise crítica de Fairclough. In: MEURER , J. L.; BONINI, A.; MOTTA-ROTH, D. (Ed.). Gêneros: teorias, métodos, debates. São Paulo: Parábola Editorial, 2005. p. 81-107.

PRAIA, J.; CACHAPUZ, A. Ciência-tecnologia-sociedade: um compromisso ético. Revista Iberoamericana de Ciencia Tecnología y Sociedad, Buenos Aires, v. 2, n. 6, p. 173-194, 2005. Disponível em: <http://www.scielo.org.ar/pdf/cts/v2n6/v2n6a10.pdf>. Acesso em: 13 out. 2014.

PRAIA, J.; CACHAPUZ, A.; GIL-PÉREZ, D. A hipótese e a experiência científica em educação em ciência: contributos para uma reorientação epistemológica. Ciência \& Educação, Bauru, v. 8, n. 2, p. 253-262, 2002. Disponível em: <http://www.scielo.br/pdf/ ciedu/v8n2/09.pdf>. Acesso em: 13 out. 2014.

SCHIBECI, R.; LEE, L. Portrayals of science and scientists, and 'science for citizenship'. Research in Science \& Technological Education, Abindgon, n. 21, n. 2, p. 177-192, 2003.

SCHUMPETER, J. Capitalism, socialism and democracy. London: Allen \& Unwin, 1970. TEDESCO, J.C. O novo pacto educativo: educação, competitividade e cidadania na sociedade moderna. São Paulo: Ática, 1999.

VILANOVA, R. A cidadania nos livros didáticos de ciências: mudança discursiva, mediações e tensões na dinâmica de produção das coleções didáticas para a educação pública. 2011. Tese (Doutorado em Educação) - Pontifícia Universidade Católica do Rio de Janeiro, Rio de Janeiro, 2011.

VILANOVA, R.; BANNELL, R. Discursos contemporâneos da cidadania e o ensino de ciências naturais. In: BANNELL, R. I.; VILANOVA, R.; FENERICH, C. (Org.). Educação para a cidadania e os limites do liberalismo. Rio de Janeiro: 7 Letras, 2011. p. 123-152. 